Abstracted/indexed in Academic Search Complete, Asia Journals Online, Bangladesh Journals Online, Biological Abstracts, BIOSIS Previews, CAB Abstracts, Current Abstracts, Directory of Open Access Journals, EMBASE/Excerpta Medica, Google Scholar, HINARI (WHO), International

\title{
Antifungal activity and brine shrimp toxicity assessment of Bulbine abyssinica used in the folk medicine in the Eastern Cape Province, South Africa
}

\author{
Cromwell Mwiti Kibiti and Anthony Jide Afolayan
}

Medicinal Plants and Economic Development (MPED) Research Center, Department of Botany, University of Fort Hare, Alice, 5700, South Africa.

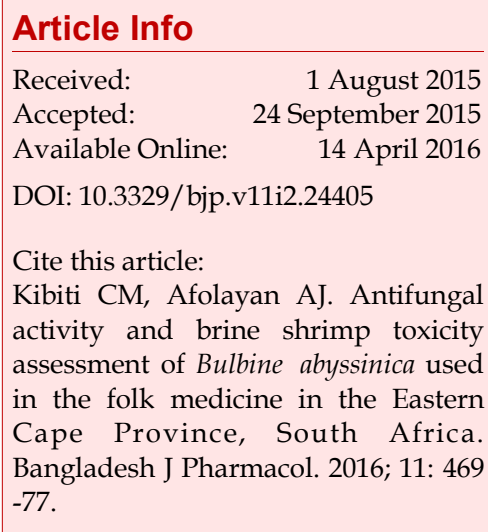

\begin{abstract}
Bulbine abyssinica is widely used in folk medicine in Eastern Cape Province, South Africa. The aim of this study was to evaluate the antifungal and toxicity potentials of essential oil, acetone and aqueous extracts of this species using standard procedures and brine shrimp test, respectively. The results showed that the species was active against the growth of Microsporum canis, Microsporum gypseum and Trichophyton rubrum among the evaluated opportunistic fungi. The toxicity results showed that the lowest cysts hatching success was observed with the essential oil, then acetone extract, with aqueous extract exhibiting the highest hatching success. Based on the criterion of toxicity indices of the lethality test, all the plant fractions exhibited $\mathrm{LD}_{50}$ values greater than $1 \mathrm{mg} / \mathrm{mL}$ hence are non-toxic. These findings indicate that $B$. abyssinica is a good source of antifungal agents.
\end{abstract}

\section{Introduction}

Fungal infections are the major secondary complications associated with diabetes mellitus (Holt, 2004). The fungal isolates including Candida albicans, Aspergillus fumigatus, A. niger, Penicillium aurantiogriesum and $P$. chrysogenum are associated with oral cavity infections (Drozdowska and Drzewoski, 2008). Trichophyton rubrum, T. mucoides and T. tonsurans cause skin and diabetic foot infections. Microsporum canis, M. gypseum, T. rubrum, T. mucoides and T. tonsurans are associated with gastro-intestinal, pulmonary and central nervous system infections (Eckhard et al., 2007; Chin-Hong, 2006). These infections are treated using the conventional antibiotics. However, their costs, side effects and resistance to these microorganisms have led to seeking alternative therapy from plant remedies (Bastos et al., 2009; Mishra et al., 2007).

Among these plant remedies, is Bulbine abyssinica A. Rich (Asphodelaceae). This is a succulent perennial herb with a rhizomatous base and grows in small clusters (Pooley, 1998). B. abyssinica is used in Southern African folk medicine against rheumatism, dysentery, cracked lips, infertility, cough, vaginal and bladder infections (Wanjohi et al., 2005). A decoction made from the whole plant parts of this species is used by traditional healers in the management of diabetes mellitus (Oyedemi et al., 2009). However, there is no available detailed pharmacological literature on the antifungal and toxicity potentials of this plant. Therefore, the objective of this study was to evaluate these properties of the essential oils, acetone and aqueous extracts of this plant using standard procedures and brine shrimp test, respectively.

\section{Materials and Methods}

\section{Plant collection and preparation}

The whole plant parts of B. abyssinica including the 
leaves, flowers, stems and roots were collected from lower Ncera location in Nkonkobe Municipality of the Eastern Cape Province, South Africa. This area lies at the latitude $30^{\circ} 00$ to $34^{\circ} 15^{\prime} \mathrm{S}$ and longitudes $22^{\circ} 45^{\prime}$ to $30^{\circ} 15^{\prime} \mathrm{E}$. It is bounded by the sea in the East and the drier Karoo in the West. The elevation ranges from sealevel to approximately 2,200 $\mathrm{m}$ in the north and the vegetation is known as the eastern cape thorn veld (Afolayan and Wintola, 2014). The voucher specimen (KibMed 2014/01) was deposited in the Giffen's herbarium, University of Fort Hare, South Africa for authentication.

\section{Extraction methods}

The plant samples were air-dried, ground to homogeneous powder and extracted using acetone and water. For acetone extraction, the solvent and ground samples were mixed on a shaker (orbital incubator shaker, Gallenkamp) at $140 \mathrm{rpm}$ ) for 48 hours, while aqueous extraction was done by boiling the samples in distilled water for $30 \mathrm{~min}$ and let to cool. These extracts were then filtered using a Buchner funnel and Whatman No. 1 filter paper. The filtrate obtained with water extraction was frozen at $-40^{\circ} \mathrm{C}$ and freeze dried for 48 hours using a freeze dryer (Vir Tis benchtop K, Vir Tis Co., USA). The acetone extracts were concentrated to dryness under reduced pressure at $57^{\circ} \mathrm{C}$ using a rotary evaporator (Strike 202 Steroglass, Italy).

The essential oil and water extraction was selected on the basis that the traditional practitioners prepare this herbal medicine as a decoction (Olaokun et al., 2013). Acetone was also selected as an extractant because it dissolves both hydrophilic and lipophilic components from plants. Acetone is also volatile and has low toxicity for use in microbial bioassays (Olaokun et al., 2013).

For essential oil extraction, the fresh plant samples were properly washed and kept in a refrigerator at $4^{\circ} \mathrm{C}$. The essential oil was extracted by hydro-distillation, according to the procedure of the European Pharmacopoeia (2002). Briefly, $250 \mathrm{~g}$ of the whole plant parts were hydro-distilled for 3 hours in an all-glass clevenger. Heat was supplied to the heating mantle $\left(50^{\circ} \mathrm{C}\right)$, and the essential oil was extracted with 4 liters of water for 3 hours until enough essential oils were collected. The average percentage yield was $0.4 \%$. The resulting extracts and essential oils were reconstituted with their respective solvents to give the desired concentrations for further in vitro bioassay activities.

\section{Antifungal analysis}

Microorganisms and media

The fungi used in this study were chosen primarily on the basis of their importance as opportunistic pathogens of humans with diabetes mellitus (Drozdowska and Drzewoski, 2008; Eckhard et al., 2007; Holt, 2004). The fungi strains of the American Type Culture Collection (ATCC) were used. These include: A. fumigatus ATTC 204305, A. niger ATCC 16888, M. canis ATCC 36299, M. gypseum ATCC 24102, P. aurantiogriesum ATCC 16025, P. chrysogenum ATCC 10106, T. rubrum ATCC 28188, T. mucoides ATCC 201382 and T. tonsurans ATCC 28942. These test organisms were purchased from Davies Diagnostics (Pty) Ltd, South Africa.

Both potato dextrose agar (PDA) and sabouraud dextrose broth (MDB) were prepared according to the manufacturer's instructions. The nutrient agar was suspended in demineralized water, boiled while stirring until completely dissolved. It was autoclaved at $121^{\circ} \mathrm{C}$ for $15 \mathrm{~min}$. The fungi were maintained at $4^{\circ} \mathrm{C}$ on PDA plates, and the inoculums for the assays were prepared by diluting scraped cell mass in $0.85 \%$ sodium chloride solution, adjusted to $0.5 \mathrm{McF}$ arland standards and confirmed spectrophotometrically at $580 \mathrm{~nm}$. The cell suspensions were finally diluted 1:100 in broth to give an approximate inoculum of $10^{4} \mathrm{CFU} / \mathrm{mL}$ as compared with McFarland standard for use in the assays (Otang et al., 2012).

\section{Antifungal susceptibility assays}

Agar well diffusion and micro dilution methods were used to determine the antifungal properties of the plant fractions against the opportunistic fungi.

\section{In vitro antifungal susceptibility test}

The agar well diffusion technique was employed as described by Otang et al. (2012) and Prabuseenivasan et al. (2006), with some modifications to determine the antifungal susceptibility test. Briefly, $100 \mu \mathrm{L}$ of 0.5 McFarland solutions of fungal strain cultures in $0.85 \%$ sterile distilled water (SDW) was placed over the surface of an agar plate and spread using a sterile inoculation loop. Three wells were cut in each agar plate with a cooled, flamed cork borer of $5 \mathrm{~mm}$ diameter, and the agar plugs removed with a sterile needle. A $50 \mu \mathrm{L}$ of the positive control drug (Nystatin) $(0.0125 \mathrm{mg} / \mathrm{mL})$ and $50 \mu \mathrm{L}$ of the corresponding extract solvent were added in the first and second wells, respectively. In the third well, $50 \mu \mathrm{L}$ of the acetone extract/aqueous extract/essential oils $(50 \mathrm{mg} / \mathrm{mL})$ was added. The culture plates were then incubated at $37^{\circ} \mathrm{C}$, and the results were observed after 3 days. The clear zone around each well was measured in $\mathrm{mm}$, indicating the activity of the plant extract against the fungal organisms.

\section{Minimum inhibitory concentration (MIC) assay}

The broth microdilution method, using 96-well microtiter plates, was employed to determine the minimum inhibitory concentration (MIC) of the plant extracts that showed antifungal activity (Otang et al., 2012). Briefly, $120 \mu \mathrm{L}$ of SDW was added into each well of the first (A) and last $(\mathrm{H})$ rows and also into all the wells of the last 
column. Then, $120 \mu \mathrm{L}$ of nutrient broth (NB) was added into each well of the second row (B). A $150 \mu \mathrm{L}$ of NB was then added into the remaining wells of the first column and $100 \mu \mathrm{L}$ into the rest of the wells from the second column rightward. Fifty microliters $(20 \mathrm{mg} / \mathrm{mL})$ of the acetone extract/ aqueous extract/essential oil were then added into the third well of the first column while $50 \mu \mathrm{L}$ of the positive (nystatin) and negative control (SDW) were separately added into the remaining wells of the first column. A 2-fold serial dilution was done by mixing the contents in each well of the first column (starting from the third row) and transferring $100 \mu \mathrm{L}$ into the second well of the same row and the procedure was repeated up to the $11^{\text {th }}$ well of the same row while discarding $100 \mu \mathrm{L}$ after the $11^{\text {th }}$ well. Therefore, the dilution of the plant fractions and the control in the wells resulted to a concentration range from $5,2.5,1.25,0.625,0.313,0.156,0.078,0.039$, $0.019,0.0098$ and $0.005 \mathrm{mg} / \mathrm{mL}$.

Thereafter, $20 \mu \mathrm{L}$ of $0.5 \mathrm{McF}$ arland fungal suspensions was inoculated into the wells except those which contained SDW. The growth of the fungi was measured by determining the absorbance at $620 \mathrm{~nm}$ with an automatic ELISA microplate reader (SynergyMx BiotekR, USA) before and after incubation. The plates were incubated at $37^{\circ} \mathrm{C}$ for 3 days. The MIC 50 was defined and recorded as the concentration of the test antifungal agent that showed 50\% inhibition of fungi growth.

\section{Brine shrimp (Artemia salina) toxicity test}

A. salina hatching and lethality assays were carried out to determine the toxicity of the plant species.

Preparation of the assay system

The assay system was prepared as described by Otang et al. (2013). Briefly, 5 petri dishes containing $30 \mathrm{~mL}$ of filtered sea water each and a 2-fold dilution was set up to yield a series of concentrations $(1,0.5,0.25,0.125$ and $0.0625 \mathrm{mg} / \mathrm{mL}$ ) of the plant fractions. A positive control was prepared in petri dishes by dissolving amphotericin B in seawater $(30 \mu \mathrm{L} / \mathrm{mL})$ while petri dishes containing sea water only, served as the blank control. The plant fractions were initially dissolved in $500 \mu \mathrm{L}$ of their corresponding solvent, and made up to the required volume using filtered seawater. The setup was allowed to stand for $30 \mathrm{~min}$ to allow the solvents evaporate (Otang et al., 2013).

\section{A. salina hatching assay}

Brine shrimp hatchability assay was evaluated by assessing the hatching success of A. salina cysts as described by Otang et al. (2013). Briefly, different concentrations ( 1 to $0.0625 \mathrm{mg} / \mathrm{mL}$ ) of the plant fractions and positive control were prepared in filtered sea water. A. salina cysts were stocked at a density of 15 individuals per petri dish containing $30 \mathrm{~mL}$ of the incubation medium at varying concentrations. The petri dishes were partly covered, incubated at $28^{\circ} \mathrm{C}$ and under constant illumination for 72 hours. The number of free nauplii in each petri dish was counted after every 12 hours till end of 72 hours. The percentage of hatchability was assessed by comparing the number of hatched nauplii with the total number of cysts stocked (Otang et al., 2013; Carballo et al., 2002).

\section{A. salina lethality assay}

Brine shrimp lethality assay was evaluated by assessing the mortality A. salina nauplii (larvae) as described by Sahgal et al. (2010). Briefly, different concentrations (1 to $0.0625 \mathrm{mg} / \mathrm{mL}$ ) of the plant fractions and positive control were prepared in filtered sea water. A suspension of nauplii (0.3 mL), containing about 30-35 larvae, was added into each petri dishes, incubated for $28^{\circ} \mathrm{C}$ and under constant illumination for 72 hours. The larvae did not receive food. To ensure that the mortality observed in the bioassay is attributed to bioactive compounds and not to starvation, a blank control (sea water) was added for comparison (Pelka et al., 2000). The petri dishes were then examined and the number of living nauplii (that exhibited movement during several seconds of observation) was counted after every 12 hours. The percentage of mortality ( $\mathrm{M} \%$ ) was calculated as;

Mortality $(\%)=($ Total nauplii - Alive nauplii $) \times 100 \% /$ Total nauplii

\section{Data analysis}

The percentage hatchability success and mortality data obtained from the 5 different concentrations of each fraction and control experiments were used to construct the dose-response curves. These were used to determine their corresponding $\mathrm{MIC}_{50}$ and $\mathrm{LC}_{50}$ values. The minimum inhibitory concentration $\left(\mathrm{MIC}_{50}\right)$ was determined as the concentration of the plant fraction/ control drug that inhibited hatching of $50 \%$ of the cysts. The $\mathrm{LC}_{50}$ was taken as the concentration required for producing 50\% mortality (Syahmi et al., 2010). LC 50 values were determined from the best-fit line obtained by linear regression analysis of the percentage lethality versus the concentration. The statistical analysis was done on MINITAB version 12 for windows. One-way analysis of variance (ANOVA) was used to test the effect of concentration and time of exposure of the plant fractions on the hatchability success, mortality of cysts and larvae, respectively, in comparison to controls (Syahmi et al., 2010).

\section{Results}

B. abyssinica was tested against nine selected diabetic status opportunistic fungi. The essential oil, acetone and aqueous extracts were inactive against the growth 
of all organisms except $M$. canis, M. gypseum and $T$. rubrum. The zones of inhibition were varying from 19.3 to $33.3 \mathrm{~mm}$ (Table I). The highest activity was observed with the essential oil which showed inhibition zones diameter of $33.3 \mathrm{~mm}$ against T. rubrum. While acetone extract's inhibitory activity was with inhibition zones diameters of 32.7 and $28.7 \mathrm{~mm}$ against $M$. canis and $M$. gypseum, respectively. The lowest activity was obtained with aqueous extract showing inhibition zone diameter of $19.3 \mathrm{~mm}$ against M. gypseum (Table I).

The lowest $\mathrm{MIC}_{50}(2.5 \mathrm{mg} / \mathrm{mL})$ observed was against $M$. canis and M. gypseum with acetone extract and against $M$. gypseum with aqueous extract. The essential oils showed MIC activity $(5 \mathrm{mg} / \mathrm{mL})$ against T. rubrum. All the plant fractions showed significantly lower activity when compared to the positive control (nystatin) against all the fungi tested $(\mathrm{p}<0.05)$ (Table II).

In toxicity assay, the hatching success of A. salina cysts incubated with different plant fractions and controls are shown in Figure 1A. The highest hatching success of $23.6 \%$ was observed in cysts incubated with the aqueous extracts of B. abyssinica. This was significantly higher than both the positive control (amphotericin B) and the sea water $(p<0.05)$. The essential oil and the acetone extract exhibited more potent inhibitory effects with hatching success of 11.6 and $12.4 \%$, respectively, which was significantly higher than positive control but lower than in sea water $(\mathrm{p}<0.05)$. The inhibitory effects of the plant fractions and their controls on hatching were estimated and expressed as MIC values (Table III). The essential oil and acetone extract exhibited significantly higher hatching inhibitory effects with MIC values of 2.9 and $2.6 \mathrm{mg} / \mathrm{mL}$, respectively, than aqueous extract $(3.3 \mathrm{mg} / \mathrm{mL})(\mathrm{p}<0.05)$ (Table III).

The hatching success of $A$. salina cysts significantly decreased with increasing concentrations of the plant fractions (Figure 1B). The hatching success of cysts incubated with essential oil (with increasing concentrations from 0.0625 to $1 \mathrm{mg} / \mathrm{mL}$ ) decreased 24 times than with aqueous extract and positive control which decreased by 4 and 6 times, respectively. The acetone extract elicited nearly 100\% hatching inhibition at $1 \mathrm{mg} / \mathrm{mL}$ (Figure 1B).

The results from this study showed that after 36 hours of exposure, hatching success of the cysts incubated in aqueous and acetone extracts only significantly increased by 1 and 1.1-fold, respectively while with essential oil, decreased significantly by 0.7 -fold (Figure $1 C)$. The increment was significantly lower than when incubated in filtered sea water (5.8-fold higher) within the same duration of time $(\mathrm{p}<0.05)$ (Figure 1C).

The effect of varying concentrations of the plant fractions on the mortality of larvae is shown in Figure 2A. The degree of mortality of nauplii was in a concentration dependent fashion. The results showed

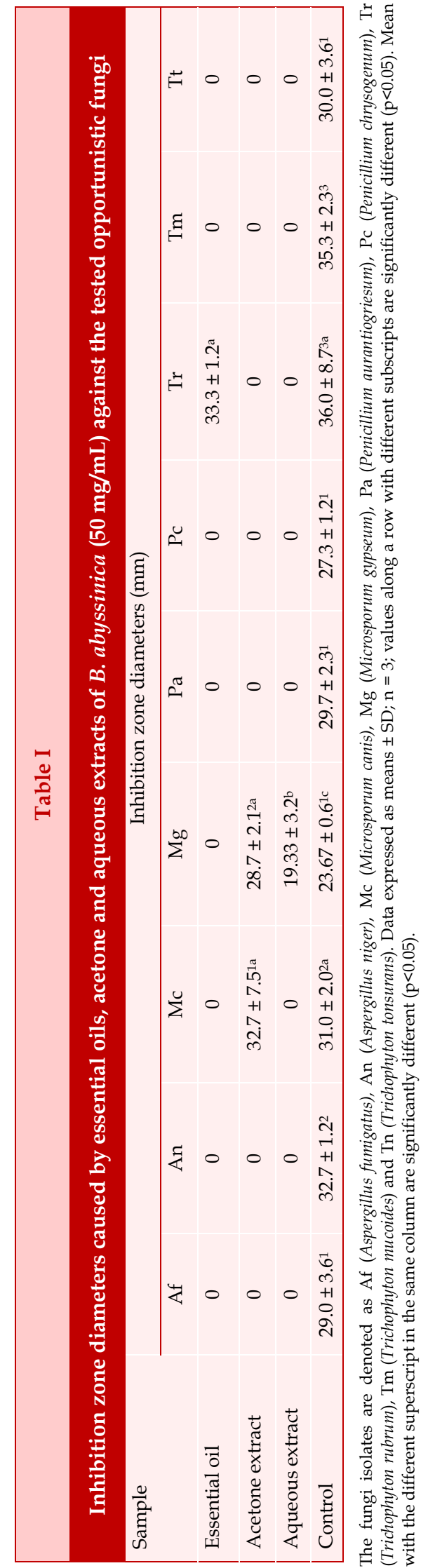


that the mortality significantly increased by 2-fold in all test fractions with increase in concentrations $(0.0625$ to 1 $\mathrm{mg} / \mathrm{mL}$ ) which was significantly similar to the positive control (Figure 2A).

The results also show that the mortality of nauplii incubated in these plant fractions increased exponentially with time (Figure 2B). After 36, 48, 60 and 72 hours of incubation in acetone extract, the mortality significantly increased by 1.1, 1.3, 1.7 and 1.9-fold, respectively. With aqueous extract, the mortality significantly increased by $2.9,3.1,4.6$ and 5.2 times more after $36,48,60$ and 72 hours, respectively $(\mathrm{p}<0.05)$. The nauplii death rate also increased by $2.5,2.7,3.1$ and 3.1-fold after incubation in essential oil over the same period of time, respectively. The increase in mortality with these plant fractions was significantly higher than the positive control at all duration times (Figure 2B) $(\mathrm{p}<0.05)$.

In overall, the mortality of nauplii was significantly similar when incubated with the essential oil, acetone extract and the amphotericin B which was significantly higher than in sea water. The aqueous extract led to significantly lower larvae mortality when compared to amphotericin B but higher than when larvae are incubated in sea water $(\mathrm{p}<0.05)$ (Figure $2 \mathrm{C})$. The estimated $\mathrm{LD}_{50}$ results were $3.12,3.18$ and $3.36 \mathrm{mg} / \mathrm{mL}$ for the essential oil, acetone and aqueous extracts, respectively (Table III).

\section{Discussion}

In this study, the results showed that the plant was active against the growth of only three fungi species. The poor growth inhibitory activity against the selected pathogenic fungi demonstrated by this plant species could be attributed to lack of bioactive antifungal agents extracted using the chosen solvents in this study. Different extraction solvents have varying degree of extraction of metabolic compounds (Lalisan et al., 2014). The fungi resistance towards the metabolites in the plant fractions might also explain the observed poor bioactivity observed with this plant remedy. These results are in agreement with similar work done by Ullah et al. (2015).

In this study, the hatching success of $A$. salina cysts incubated with different plant fractions showed that the highest hatching success of cysts was achieved when incubated with the aqueous extract. This might be an indication that it could be less toxic and safer among the three fractions. The hatching success significantly decreased with increasing concentrations of the plant fractions in a dose dependent manner with the acetone extract eliciting $100 \%$ hatching inhibition at $1 \mathrm{mg} / \mathrm{mL}$. This could be explained by presence of toxic metabolites in the fraction or high concentration of the

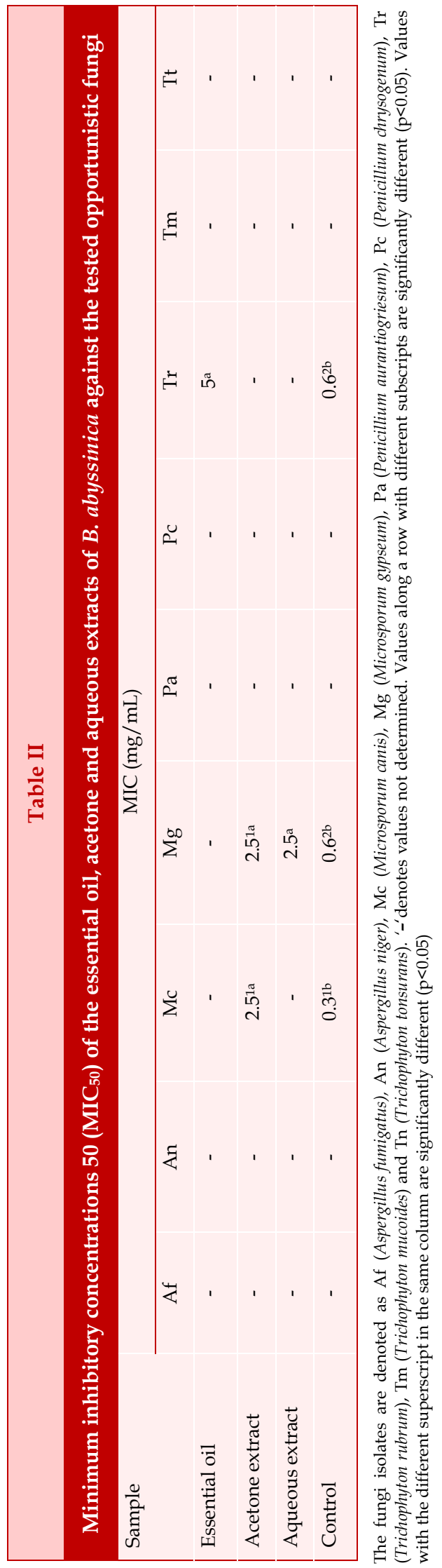


metabolites. The continued hatching of cysts when incubated at high test concentration $(1 \mathrm{mg} / \mathrm{mL})$ with essential oil and aqueous extracts can be predicted to be as a result of tolerance property by cysts at higher concentrations. A. salina cysts possess a resistant cyst stage which makes it tolerant to a wide range of $\mathrm{pH}$ ranging from freshwater to saturated saline (Caldwell et al., 2003). Similar findings by Otang et al. (2013)

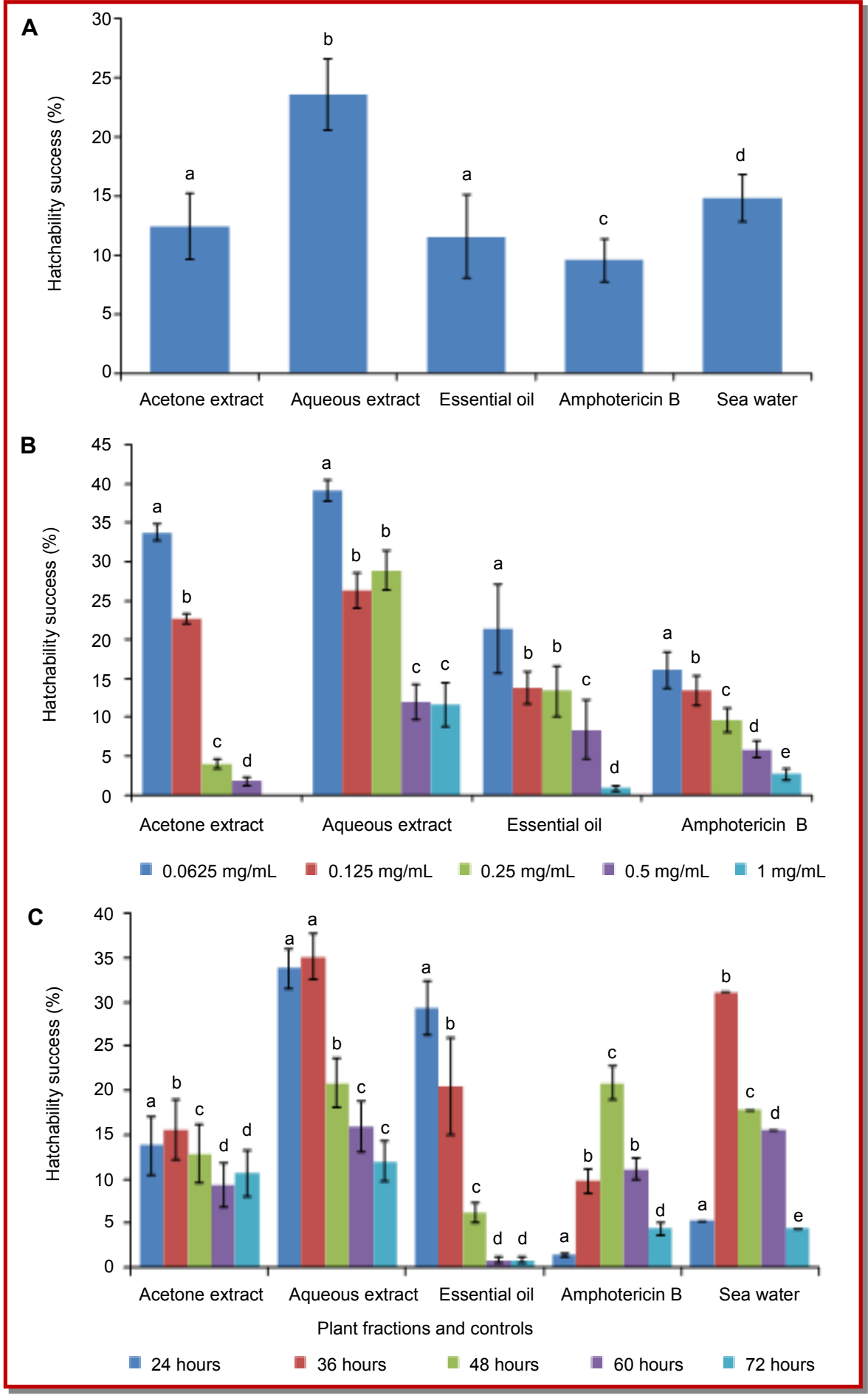

Figure 1: Percentage hatching success of A. salina cysts. (A) Incubated in different plant fractions and controls; (B) In different concentrations of the plant extracts and control; (C) In different durations in the plant fractions and controls. The values are means of experiments/concentrations for each plant fraction/control $\pm \mathrm{SD}$ of three replicates. Hatching success marked with different letters is significantly different $(\mathrm{p}<0.05)$ 


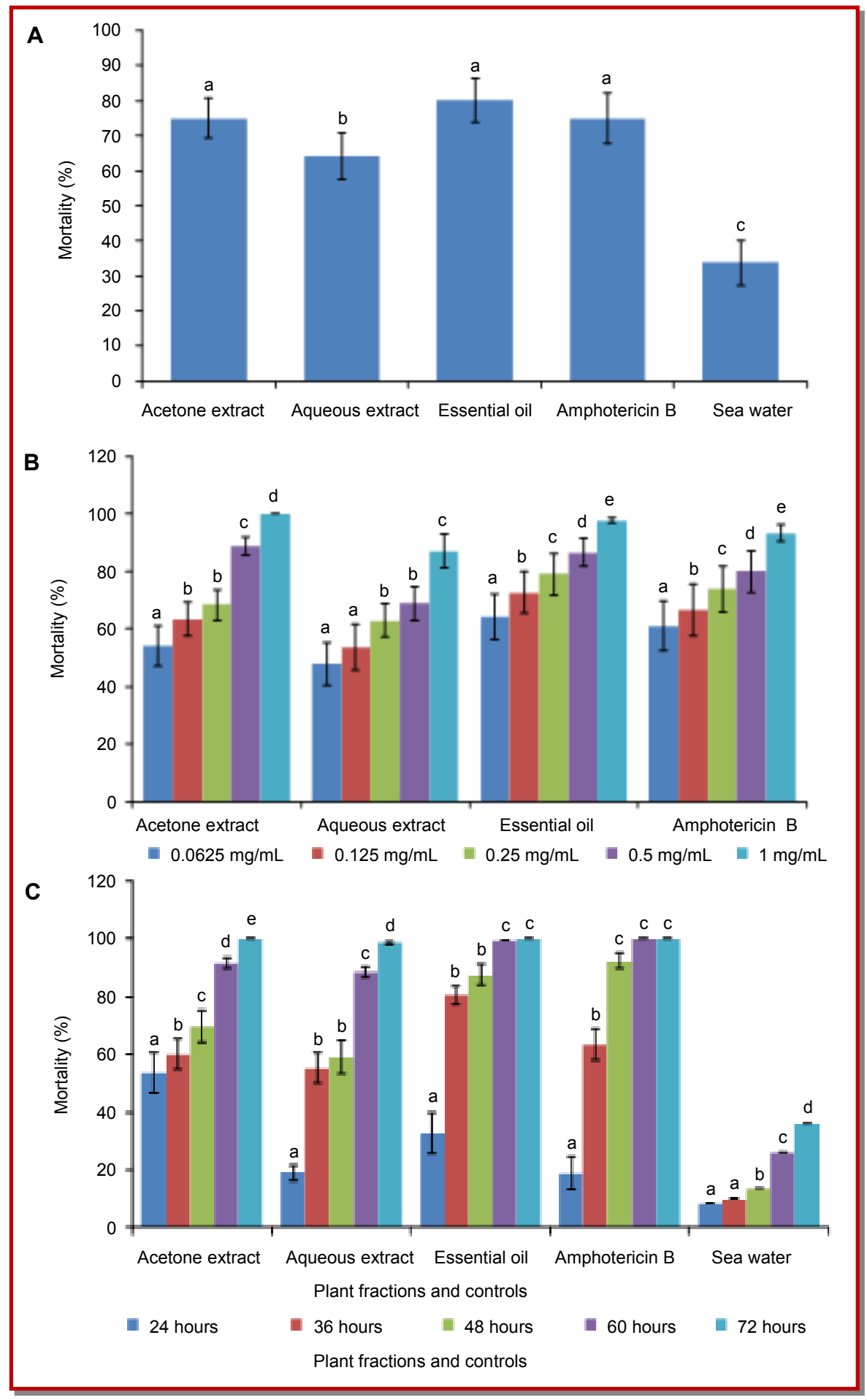

Figure 2: Percentage mortality of A. salina nauplii. (A) Incubated in different plant fractions and controls; (B) In different concentrations of the plant extracts and control; (C) In different durations in the plant fractions and controls. The values are means of experiments/concentrations for each plant fraction/control $\pm \mathrm{SD}$ of three replicates. Percentage mortality of fraction/control marked with different letters is significantly different $(\mathrm{p}<0.05)$

support this resistant cyst stage hypothesis.

The results showed that there was a poor cyst hatching into larvae after 36 hours when incubated with the plant fractions. In BST, it is known that the optimal hatching of cysts to yield a large number of larvae (nauplii) is achieved within 48 hours (Meyer et al., 1982). The low hatchability success observed with this plant species could be predicted to the presence of 


\section{Table III}

Hatchability and lethality of A. salina incubated in different concentrations of acetone extract, aqueous extracts and essential oils of $B$. abyssinica

\begin{tabular}{|lccc|c|c|c|}
\hline Sample & \multicolumn{3}{c}{ Hatchability assay } & \multicolumn{3}{c|}{ Hatchability assay } \\
\cline { 2 - 7 } & MIC 50 $(\mathrm{mg} / \mathrm{mL})$ & Regression equation & $\mathrm{R}^{2}(\%)$ & $\mathrm{LD}_{50}(\mathrm{mg} / \mathrm{mL})$ & Regression equation & $\mathrm{R}^{2}(\%)$ \\
Acetone extract & 2.55 & $\mathrm{Y}=8.84 \mathrm{x}-14.09$ & 86.9 & 3.18 & $\mathrm{Y}=11.72 \mathrm{x}+39.84$ & 96.0 \\
Aqueous extract & 3.26 & $\mathrm{Y}=6.93 \mathrm{x}+2.76$ & 86.6 & 3.36 & $\mathrm{Y}=9.38 \mathrm{x}+35.96$ & 94.9 \\
Essential oil & 2.90 & $\mathrm{Y}=4.62 \mathrm{x}-2.31$ & 94.1 & 3.12 & $\mathrm{Y}=8.10 \mathrm{x}+55.80$ & 99.1 \\
Amphotericin B & 2.96 & $\mathrm{Y}=3.42 \mathrm{x}-0.71$ & 99.8 & 3.29 & $\mathrm{Y}=7.78 \mathrm{x}+51.65$ & 96.8 \\
\hline
\end{tabular}

The toxicity regression equation used to estimate the MIC $50(\mathrm{mg} / \mathrm{mL})$ and $\mathrm{LD}_{50}(\mathrm{mg} / \mathrm{mL})$ values of acetone extract, aqueous extract, essential oil and amphotericin B (positive control) in hatchability success and lethality test in brine shrimp test. R ${ }^{2}$ (\%) denotes the coefficient of determination of the regression equation

chemical metabolites which probably altered the development of $A$. salina embryos. Similar studies have shown that toxins inhibit the progression of early developmental stages of A. salina (Vasconcelos et al., 2010).

The A. salina resistant cyst stage property at higher salinities makes the hatchability test less desirable assay for preliminary herbal remedies' toxicity test. The use of hatched larvae (nauplii) has been used to by-pass this toxin tolerant cyst stage hence lethality assay involving nauplii was employed (Caldwell et al., 2003; Otang et al., 2013). The results showed that the effect of different concentrations all the plant fractions on the mortality of larvae was in a concentration dependent fashion, hence this can be postulated that though these are toxicological data, this plant possesses pharmacological activity based on the dosage administered (Otang et al., 2013).

The mortality of nauplii incubated in these plant fractions increased exponentially with time with the highest mortality observed at 72 hours with all the fractions. The increment in mortality with these plant fractions was significantly higher than positive control at all duration times. The nauplii attain the second and third instars of their life cycle within 48 hours hence reveal their greatest sensitivity to toxins at this time (Sreejamole and Radhakrishnan, 2013). However, the findings of this study indicate that the maximum sensitivity was reached after 72 hours of exposure. This is probably due to presence of nutritive metabolites than toxic chemicals. Moreover, A. salina nauplii are known to stay alive for 48 hours without food due to enrichments from the yoke-sac (Pelka et al., 2000). Therefore, the nauplii survival observed after 60 hours in this study with all the plant fractions could also be explained by the presence of the non-toxic metabolites in the plant species.

In this study, the mortality of nauplii was significantly higher when incubated with essential oil and acetone extract than with aqueous extract of this species with estimated $\mathrm{LD}_{50}$ values of $3.12,3.18$ and $3.36 \mathrm{mg} / \mathrm{mL}$, respectively. These estimated $L_{50}$ values suggests that these plant fractions exhibited low mortality potential with $\mathrm{LD}_{50}$ values greater than $1000 \mu \mathrm{g} / \mathrm{mL}$. Therefore, based on criterion of toxicity, these plant fractions can be regarded as non-toxic (Meyer et al., 1982; Bastos et al., 2009).

\section{Conclusion}

Bulbine abyssinica could serve as a source of antifungal agents against the susceptible fungi isolates especially the Microsporum and Trichophyton genus which are known be resistance to antibiotics and cause deleterious gastrointestinal, central nervous system, skin and foot infections in diabetic patients

\section{Acknowledgement}

This research was supported by grants from Govan Mbeki Research and Development Center, University of Fort Hare, South Africa.

\section{Conflict of Interest}

The authors have no conflicting interest.

\section{References}

Afolayan AJ, Wintola OA. A survey of medicinal plants used in the treatment of dysentery in Amathole district municipality, South Africa. Pakistan J Bot. 2014; 46: 1685-92.

Bastos MLA, Lima MRF, Conserva LM, Andrade VS, Rocha EMM, Lemos RPL. Studies on the antimicrobial activity and brine shrimp toxicity of Zeyheria tuberculosa (Vell.) Bur. (Bignoniaceae) extracts and their main constituents. Ann Clin Microbiol Antimicrob. 2009.

Caldwell GS, Bentley MG, Olive PJW. The use of a brine shrimp (Artemia salina) bioassay to assess the toxicity of 
diatom extracts and short chain aldehydes. Toxicon 2003; 42: 301-06.

Carballo JL, Hernandez-Inda ZL, Perez P, Garcia-Gravalos MD. A comparison between two brine shrimp assays to detect in vitro cytotoxicity in marine natural products. BMC Biotechnol. 2002; 2: 17.

Chin-Hong PV. Infections in patients with diabetes mellitus: Importance of early recognition, treatment, and prevention. Infectious Diseases. 2006; 6: 72-81.

Council of Europe, European Pharmacopoeia Commission European Directorate for the Quality of Medicines and Healthcare. European Pharmacopoeia. $4^{\text {th }}$ ed. Strasbourg, Council of Europe, 2002.

Drozdowska A, Drzewoski J. Mycoses in diabetes-difficult diagnostic and therapeutic problem. Review of literature. Diabetologia Doświadczalna Kliniczna. 2008; 8: 1-11.

Eckhard M, Lengler A, Liersch J, Bretzel RG, Mayser P. Fungal foot infections in patients with diabetes mellitus: Results of two independent investigations. Mycoses 2007; 50: 14-19.

Holt RIG. Diagnosis, epidemiology and pathogenesis of diabetes mellitus: An update for psychiatrists. Brit J Psychiat. 2004; 184: 55-63.

Lalisan JA, Nuneza OM, Uy MM. Brine shrimp (Artemia salina) bioassay of the medicinal plant Pseudelephantopus spicatus from Iligan City, Philippines. Int Res J Biol Sci. 2014; 3: 47-50.

Meyer BN, Ferrigni NR, Putnam JE, Jacobsen LB, Nichols DE, McLaughlin JL. Brine shrimp: A convenient general bioassay for active plant constituents. J Med Plants Res. 1982; 45: 3134 .

Mishra NN, Prasad T, Sharma N, Paysi A, Prasad R, Gupta DK, Singh R. Pathogenicity and drug resistance in Candida albicans and other yeast species: A review. Acta Microbiol Immunol Hung. 2007; 54: 201-35.

Olaokun OO, McGaw LJ, Eloff JN, Naidoo V. Evaluation of the inhibition of carbohydrate hydrolyzing enzymes, antioxidant activity and polyphenolic content of extracts of ten African Ficus species (Moraceae) used traditionally to treat diabetes. BMC Complement Altern Med. 2013; 13: 94.

Otang WM, Grierson DS, Ndip RN. Antifungal activity of Arctotis arctotoides (L.f.) O. Hoffm. and Gasteria bicolor Haw. against opportunistic fungi associated with human immunodeficiency virus/acquired immunodeficiency syndrome. Pharmacogn Mag. 2012; 8: 135-40.

Otang WM, Grierson DS, Ndip RN. Assessment of potential toxicity of three South African medicinal plants using the brine shrimp (Artemia salina) assay. Afr J Pharm Pharmacol. 2013; 7: 1272-79.

Oyedemi SO, Bradley G, Afolayan AJ. Ethnobotanical survey of medicinal plants used for the management of diabetes mellitus in the Nkonkobe municipality of South Africa. J Med Plants Res. 2009; 3: 1040-44.

Pelka M, Danzl C, Distler W, Petschelt A. A new screening test toxicity testing of dental materials. J Dent. 2000; 28: 341-45.

Pooley E. A field guide to wild flowers of KwaZulu-Natal and the Eastern Region. Natal Flora Trust Publications, Durban, South Africa, 1998.

Prabuseenivasan S, Jayakumar M, Ignacimuthu S. In vitro antibacterial activity of some plant essential oils. BMC Complement Altern Med. 2006; 6: 39.

Sahgal G, Ramanathan S, Sasidharan S, Mordi MN, Ismail S, Mansor SM. Brine shrimp lethality and acute oral toxicity studies on Swietenia mahagoni (Linn.) Jacq. seed methanolic extract. Pharmacognosy Res. 2010; 2: 215-20.

Sreejamole KL, Radhakrishnan CK. Antioxidant and cytotoxic activities of ethyl acetate extract of the Indian green mussel Perna viridis. Asian J Pharm Clin Res. 2013; 6: 197-201.

Syahmi ARM, Vijayarathna S, Sasidharan S, Latha LY, Kwan YP, Lau YL, Shin LN, Chen Y. Acute oral toxicity and brine shrimp lethality of Elaeis guineensis Jacq., (oil palm leaf) methanol extract. Molecules 2010; 15: 8111-21.

Ullah R, Bakht J, Shafi M. Antimicrobial and anti-oxidant potential of Periploca hydaspidis. Bangladesh J Pharmacol. 2015; 10: 645-51.

Vasconcelos V, Azevedo J, Silva M, Ramos V. Effects of marine toxins on the reproduction and early stages development of aquatic organisms. Mar Drugs. 2010; 8: 59-79.

Wanjohi JM, Yenesew A, Midiwo JO, Heydenreich M, Peter MG, Dreyer M, Reichert M, Bringmann G. Three dimeric anthracene derivatives from the fruits of Bulbine abyssinica. Tetrahedron 2005; 61: 2667-74.

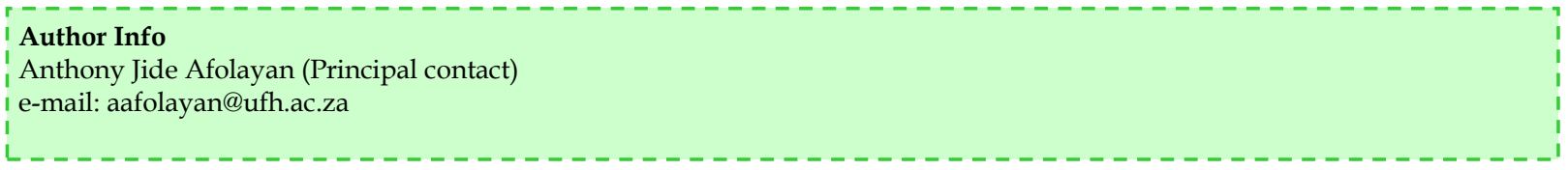




\section{Your feedback about this paper}

1. Number of times you have read this paper 0

2. Quality of paper

$\bigcirc$ Excellent $\quad \mathrm{\text {Good }} \bigcirc$ Moderate $\bigcirc$ Not good

3. Your comments

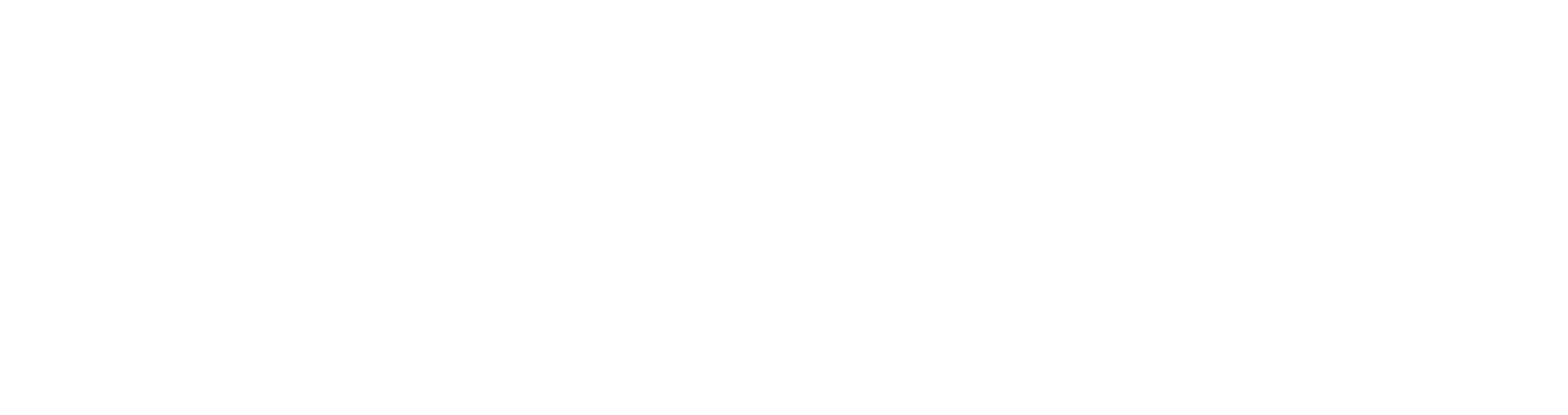

